\title{
The Distribution of Ammonia and Its Photochemical Products on Jupiter
}

\author{
S. K. ATREYA, ${ }^{1}$ T. M. DONAHUE, ${ }^{1}$ AND W. R. KUHN ${ }^{1,2}$ \\ Department of Atmospheric and Oceanic Science, Space Physics Research Laboratory, \\ The University of Michigan, Ann Arbor, Michigan 48109
}

Received June 15, 1976; revised January 3, 1977

\begin{abstract}
Altitude profiles of ammonia and its photochemical products are generated in the light of the new measurements of the Jovian temperature structure, eddy transport coefficient, improved chemical scheme, and rate constants. Realistic limits are placed on the concentration of hydrazine which may participate in the recycling of ammonia on Jupiter. The maximum hydrazine ice production rate is calculated to be about $1.3 \mathrm{mg} \mathrm{m}^{-2} /$ Jovian day. The distribution of nitrogen gas is presented with and without supersaturation of hydrazine. The nitrogen mixing ratio near the ammonia cloud top is estimated to be in the range of $10^{-9}$ to $10^{-11}$. An appreciable latitudinal variation in the ammonia concentration is expected.
\end{abstract}

\section{INTRODUCTION}

Several new laboratory and in situ measurements pertinent to the problem of ammonia on Jupiter have become available since Strobel (1973) published his calculations of the $\mathrm{NH}_{3}$ photochemistry. The Jovian temperature profile down to the ammonia cloud top has been inferred with a degree of accuracy adequate for the prediction of some interesting atmospheric properties from the dala collected by both the infrared radiometer and the radio occulation techniques used on Pioneers 10 and 11 . New insight into the possible range of values for the eddy mixing coefficient is provided by the Jovian Lyman $\alpha$ airglow measurements. Additional chemical reactions and improved laboratory measurements of rate constants of some pertinent reactions are now available. In view of this new knowledge and the possible

${ }_{1}$ The authors have contributed equally to this study.

${ }^{2}$ Also at Chemical Evolution Branch, NASAAmes Research Center, California 94035.
Jupiter Orbiter Probe Mission whose atmospheric sampling instruments would be designed to measure the various gaseous species in the lower atmosphere of Jupiter, we have carried out calculations which yield new estimates of the distribution of ammonia and its photochemical products. Sensitivity studies have also been made for several possible variations of the eddy transport coefficient. In addition, the question of hydrazine $\left(\mathrm{N}_{2} \mathrm{H}_{4}\right)$ condensation is discussed and extreme profiles of "gaseous" hydrazine as a function of Jovian altitude are generatcd along with the corresponding distribution of nitrogen gas. Some insight into the diurnal and latitudinal behavior of the gases is provided and important new or improved laboratory measurements are identified.

\section{MODELS}

For the present calculations we assume the temperature profile as inferred from the Pioneers 10 and 11 data (Hunten, 1976). The temperature varies from $165^{\circ} \mathrm{K}$ 
TABLE I

Relevant Chemical Reactions and Associnted Rape Constants

\begin{tabular}{|c|c|c|c|}
\hline $\begin{array}{c}\text { Reaction } \\
\text { number }\end{array}$ & Reaction & Rate constant ${ }^{a}$ & Reference \\
\hline$R 1$ & $\mathrm{NH}_{3}+h \nu \rightarrow \mathrm{NH}_{2}(X)+\mathbf{H}$ & $J\left(\mathrm{NH}_{3}\right)$ & See text \\
\hline$R 2$ & $\mathrm{NH}_{2}(X)+\mathrm{H} \stackrel{+M}{\rightarrow} \mathrm{NH}_{3}$ & $k_{2}=6 \times 10^{-30}[M] /\left(1+3 \times 10^{-20}[M]\right)$ & Gorden et al. (1971) \\
\hline$R 3$ & $\mathrm{NH}_{2}(X)+\mathrm{NH}_{2}(X) \stackrel{+M}{\rightarrow} \mathrm{N}_{2} \mathrm{H}_{4}$ & $k_{3}=1 \times 10^{-10}$ & Gorden et al. (1971) \\
\hline$R 4$ & $\mathrm{~N}_{2} \mathrm{H}_{4}+\mathrm{H} \rightarrow \mathrm{N}_{2} \mathrm{H}_{3}+\mathrm{H}_{2}$ & $k_{4}=9.87 \times 10^{-12} \exp ^{(-\mathrm{t} 198 / T)}$ & Stief and Payne (1976) \\
\hline$R 5$ & $\mathrm{~N}_{2} \mathrm{H}_{4}+h \nu \rightarrow \mathrm{N}_{2} \mathrm{H}_{3}+\mathrm{H}$ & $J\left(\mathrm{~N}_{2} \mathrm{H}_{4}\right)$ & See text \\
\hline$\pi 6$ & $\mathrm{~N}_{2} \mathrm{H}_{3}+\mathrm{H} \rightarrow 2 \mathrm{NH}_{2}$ & $k_{6}=2.7 \times 10^{-12}$ & Gehring et al. (1969) \\
\hline$R 7$ & $\mathbf{H}+\mathbf{H}+M \rightarrow \mathbf{H}_{2}+M$ & $k_{7}=8 \times 10^{-33}(300 / T)^{0.6}$ & Ham et al. (1970) \\
\hline$R 8$ & $\mathrm{~N}_{2} \mathrm{H}_{3}+\mathrm{N}_{2} \mathrm{H}_{3} \rightarrow 2 \mathrm{NH}_{3}+\mathrm{N}_{2}$ & $k_{s} \ll k_{9}$ & $\begin{array}{l}\text { Stief }(1976, \text { personal } \\
\text { communication) }\end{array}$ \\
\hline$R 9$ & $\begin{aligned} \mathrm{N}_{2} \mathrm{H}_{3}+\mathrm{N}_{2} \mathrm{H}_{3} & \rightarrow \mathrm{N}_{2} \mathrm{H}_{4}+\mathrm{N}_{2} \mathrm{H}_{2} \\
& \rightarrow \mathrm{N}_{2} \mathrm{H}_{4}+\mathrm{N}_{2}+\mathrm{H}_{2}\end{aligned}$ & $k_{9}=6 \times 10^{-11}$ & $\begin{array}{l}\text { Stief (1976, personal } \\
\text { communication) }\end{array}$ \\
\hline
\end{tabular}

a Rate constants $\left(k^{\prime} \mathrm{s}\right)$ are given in $\mathrm{cm}^{3} \mathrm{sec}^{-1}$ for two-body reactions and in $\mathrm{cm}^{6} \mathrm{sec}^{-1}$ for three-body reactions. Photodissociation rates $J\left(\mathrm{NH}_{3}\right)$ and $J\left(\mathrm{~N}_{2} \mathrm{H}_{4}\right)$ are given in $\sec ^{-1}$.

at 1000 mbar to $148^{\circ} \mathrm{K}$ at 10 mbar with a distinct temperature inversion $\left(110^{\circ} \mathrm{K}\right)$ around the 100-mbar pressure level. The Pioneer 10 Lyman $\alpha$ airglow measurements (Carlson and Judge, 1974) seem to indicate an eddy diffusion coefficient of the order of $3 \times 10^{8 \pm 1} \mathrm{~cm}^{2} \mathrm{sec}^{-1}$ with a highly uncertain homopause. However, the recent OAOCopernicus measurements (Barker, 1976) give a Lyman $\alpha$ intensity which may be up to four times greater than that interpreted by Carlson and Judge from their photometer data. Thus the Copernicus data imply a smaller value of eddy diffusion coefficient $K$. We have made calculations with $K \propto 1 / M$ and $K \propto 1 / M^{1 / 2}$ (see, e.g., Lindzen, 1971), both with an assumed tropopause value of $K_{0}=2 \times 10^{4} \mathrm{~cm}^{2} \mathrm{sec}^{-1}$ after Tomasko (1974). Sensitivity studies are also done with $K_{0}=2 \times 10^{3}$ and $2 \times 10^{5}$ $\mathrm{cm}^{2} \mathrm{sec}^{-1}$. We also consider the case with constant $K$ of $2 \times 10^{4} \mathrm{~cm}^{2} \mathrm{sec}^{-1}$, the value assumed by Strobel (1973). The $K \propto 1 / M^{1 / 2}$ variation appears the most realistic; a $1 / M$ variation produces an unacceptably high value of the eddy diffusion coefficient at the homopause.

The relevant chemical reactions and the associated rate constants are listed in Table I. Photolysis of ammonia longward of $1600 \AA$ results in the formation of the amidogen radical $\mathrm{NH}_{2}(X)$ in the ground state. Reaction of $\mathrm{NH}_{2}(X)$ with hydrogen recycles part of the ammonia while reaction with itself leads to the formation of hydrazine. Photolysis of gaseous $\mathrm{N}_{2} \mathrm{H}_{4}$ then gives the $\mathrm{N}_{2} \mathrm{H}_{3}$ radical which reacts with $\mathrm{H}$ to form $\mathrm{NH}_{2}$ by the extraction reaction $R 6$. $\mathrm{N}_{2} \mathrm{H}_{3}$ reacts with itself to produce $\mathrm{N}_{2} \mathrm{H}_{4}$ and $\mathrm{N}_{2}(R 9)$; the rate constant for $R 8$ is much smaller than that for $R 9$ (Stief, 1976, personal communication). The chemical reactions leading to the production of $\mathrm{N}_{2}$ in this paper differ from Strobel's (1973) in that he considers production of $\mathrm{N}_{2}$ directly from the photolysis of $\mathrm{N}_{2} \mathrm{H}_{4}$ and from the extraction reaction: $\mathrm{N}_{2} \mathrm{H}_{3}$ $+\mathrm{H} \rightarrow \mathrm{N}_{2}+2 \mathrm{H}_{2}$. Photolysis products of $\mathrm{N}_{2} \mathrm{H}_{4}$ by absorption of solar radiation longward of $1600 \AA$ may be as follows:

$$
\begin{aligned}
\mathrm{N}_{2} \mathrm{H}_{4}+h \nu & \rightarrow \mathrm{H}+\mathrm{N}_{2} \mathrm{H}_{3} & & R 5 \\
& \rightarrow 2 \mathrm{NH}_{2} & & R 10 \\
& \rightarrow \mathrm{NH}_{3}+\mathrm{NH} & & R 11 \\
& \rightarrow \mathrm{H}_{2}+\mathrm{N}_{2} \mathrm{H}_{2} & & R 12 .
\end{aligned}
$$

Only the first one of these processes, $R 5$, is dominant, while the rest have extremely low quantum yield (see Schurath and Schindler, 1970; Stief and Payne, 1976).

The rate constants $k_{2}, k_{3}$, and $k_{7}$ listed in Table I are the same as those used by 


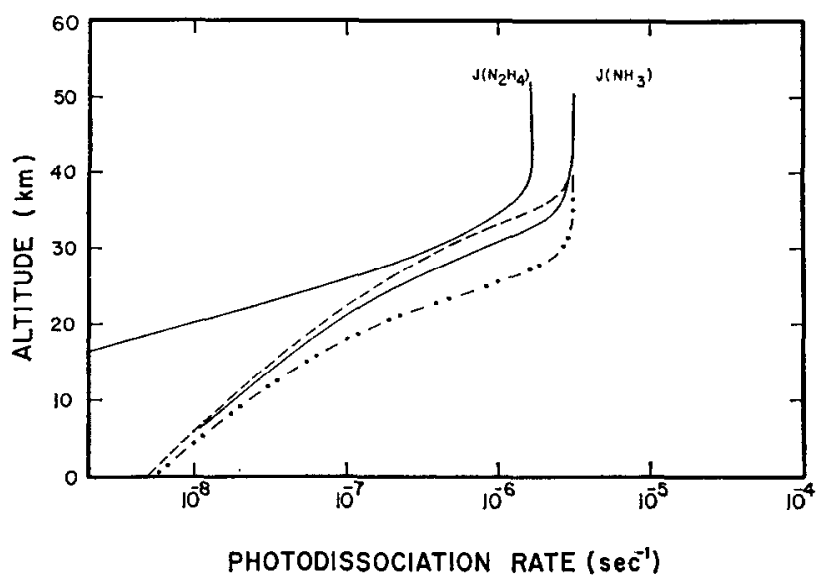

Fig. 1. Variation of ammonia and hydrazine photodissociation rates, $J\left(\mathrm{NH}_{3}\right)$ and $J\left(\mathrm{~N}_{2} \mathrm{H}_{4}\right)$, with height for several different atmospheric models. The reference altitude $z=0 \mathrm{~km}$ is taken at the 1-atm-pressure level. All model atmospheres have temperature varying with altitude in accordance with Hunten (1976). The rate constant $k_{4}$ is taken from the measurements of Stief and Payne (1976). The curve with $K=2 \times 10^{4} \mathrm{~cm}^{2} \mathrm{sec}^{-1}$ refers to the model in which the eddy diffusion coefficient is constant over the entire altitude range. The other two curves correspond to $K$ varying inversely and inversely as the square root of the atmospheric number density, $M$, with reference value of $K=K_{0}=2 \times 10^{4} \mathrm{~cm}^{2} \mathrm{sec}^{-1}$ at the 1-atm-pressure level $\left(M=2.9 \times 10^{19} \mathrm{~cm}^{-3}\right) .-\cdots, T(z), K=2 \times 10^{4} \mathrm{~cm}^{2} \mathrm{sec}^{-1}$ (constant); - $, T(z), K \propto 1 /$ $M^{1 / 2} ;---, T(z), K \propto 1 / M$.

Strobel (1973). Stief and Payne (1976) indicate that in the relevant temperature range $k_{4}$ may be up to a factor of 35 lower than the Francis and Jones (1971) value used in earlier calculations.

Photoabsorption by ammonia was calculated for wavelengths between 1600 and $2300 \AA$; at shorter wavelengths solar radiation is absorbed by methane whose abundance above the ammonia cloud top is substantially greater than that of ammonia. Solar fluxes are from Ackerman (1971) and photoabsorption cross sections of $\mathrm{NH}_{3}$ and $\mathrm{N}_{2} \mathrm{H}_{4}$ are from Watanabe (1954), Thompson et al. (1963), and Schürgers and Welge (1968). Solar flux and cross sections were averaged over a $10-\AA$ interval; because of the structure in the ammonia cross sections, the averaging interval is inportant. As discussed later, the major uncertainty in the calculations results from the choice of the eddy diffusion coefficient. Therefore we have not included secondary effects such as depletion of solar flux by
Rayleigh scattering (Strobel, 1973) and aerosols. For the "global average" model the solar flux was decreased by a factor of 0.5 and the mass path was doubled. A calculation for a latitude of $75^{\circ}$ was also carricd out; the effective zenith angle $\xi$ (determined by averaging $\cos \xi$ over the daylight hours) is $80.5^{\circ}$ which yields a solar attenuation of 0.165

One-dimensional steady-state coupled continuity and eddy transport equations were solved by a generalized NewtonRaphson's method (see, e.g., Ames, 1969). The step size was $1 \mathrm{~km}$ and the convergence criterion was $5 \%$. With the exception of $\mathrm{N}_{2}$, the system was treated as a two-point boundary value problem. Large variations in the boundary values caused changes in the solutions within only a few kilometers of the boundaries located at $0 \mathrm{~km}$ (number density of $2.9 \times 10^{19} \mathrm{~cm}^{-3}$ ) and $40 \mathrm{~km}$. A flux lower boundary condition was assumed for nitrogen so that the downward flux was approximatcly equal to half 
the upward flux of ammonia; thus our solutions represent a lower limit to $\mathrm{N}_{2}$ concentrations.

\section{RESULTS AND DISCUSSION}

Photodissociation rates of ammonia and hydrazine, $J\left(\mathrm{NH}_{3}\right)$ and $J\left(\mathrm{~N}_{2} \mathrm{H}_{4}\right)$, are shown in Fig. 1 for the various assumptions on the model atmosphere. We show only one profile for $\mathrm{N}_{2} \mathrm{H}_{4}$ corresponding to the atmospheric model in which $K \propto 1 / M^{1 / 2}$ (standard case). This calculation was based on the assumption that all the $\mathrm{N}_{2} \mathrm{H}_{4}$ generated in reaction $R 3$ of Table $\mathrm{I}$ is in the gaseous state. As we shall see later, if hydrazine condenses at its saturation vapor pressure then the dissociation rate will simply be the value corresponding to an optical depth of zero. The photodissociation rates of $\mathrm{NH}_{3}$ can be as much as a factor of 4 greater than Strobel's (1973) values. This difference is attributed to revised solar flux data which in some spectral regions are twice as large as those used by Strobel. Also our spectral interval of $10 \AA$ allows a realistic reproduction of the absorption cross sections of $\mathrm{NH}_{3}$.

The height distributions of ammonia and its photolysis products in terms of volume mixing ratios are shown in Fig. 2. The curves refer to an eddy diffusion coefficient $K \propto 1 / M^{1 / 2}$. The solid line curves for $\mathrm{N}_{2} \mathrm{H}_{4}$, $\mathrm{N}_{2} \mathrm{H}_{3}$, and $\mathrm{N}_{2}$ were calculated on the assumption that all the $\mathrm{N}_{2} \mathrm{H}_{4}$ resulting from the reaction $R 3$ is in the gascous phase. One would not expect this to be the case; e.g., at $20 \mathrm{~km}$ where the temperature is $130^{\circ} \mathrm{K}$, the saturation number density is estimated to be about $10^{5} \mathrm{~cm}^{-3}$ while the calculated density is $10^{10} \mathrm{~cm}^{-3}$. Such a degree of supersaturation is most unlikely.

Our calculations also show in Fig. 2 the $\mathrm{N}_{2} \mathrm{H}_{4}, \mathrm{~N}_{2} \mathrm{H}_{3}$, and $\mathrm{N}_{2}$ distribution if hydrazine ice forms at the saturation vapor pressure. We have calculated the sublimation vapor pressure from data of Audreith

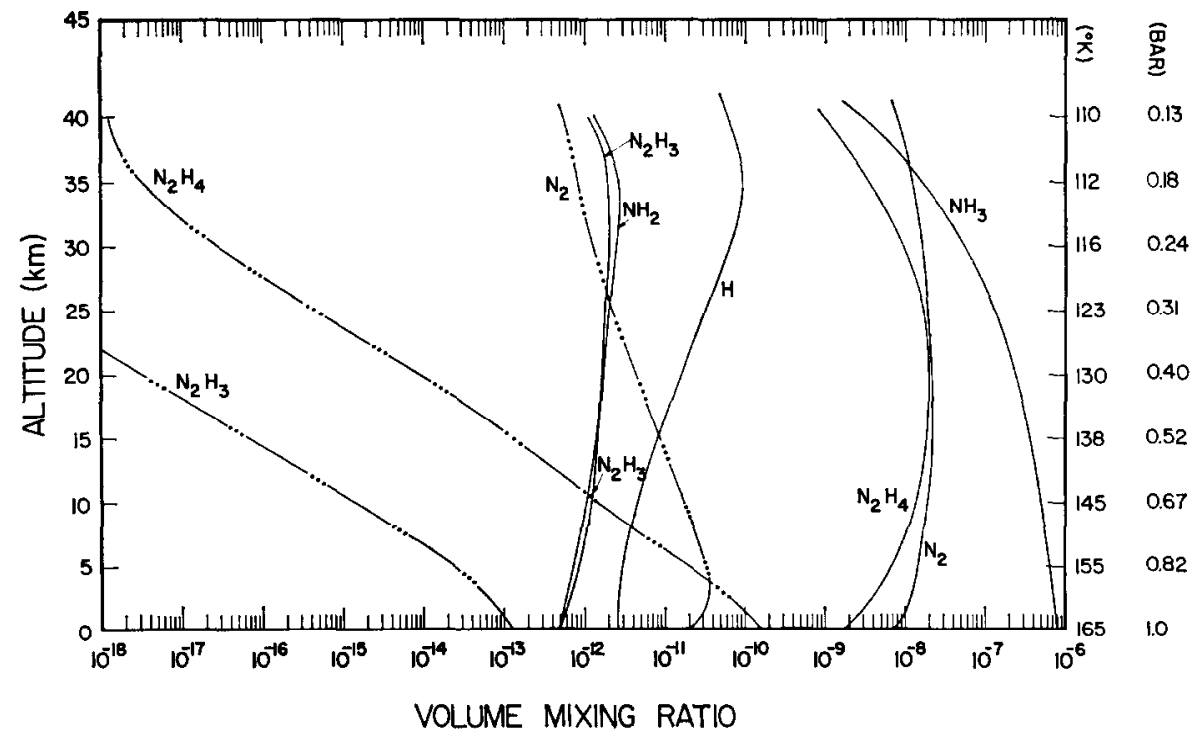

Fig. 2. Altitude profiles of volume mixing ratios of ammonia and its photochemical products for Hunten (1976) temperature profile and the $K \propto 1 / M^{1 / 2}$ atmospheric model (solid line curves). The temperatures and pressures given on the right ordinate correspond to the altitudes shown on the left. The rate constant $k_{4}$ is that of Stief and Payne (1976). Curves illustrated by -...for $\mathrm{N}_{2} \mathrm{H}_{4}$ and $\mathrm{N}_{2} \mathrm{H}_{3}$ assume a saturation vapor mixing ratio. The resultant $\mathrm{N}_{2}$ mixing ratio profile is shown by the - ...- curve. 


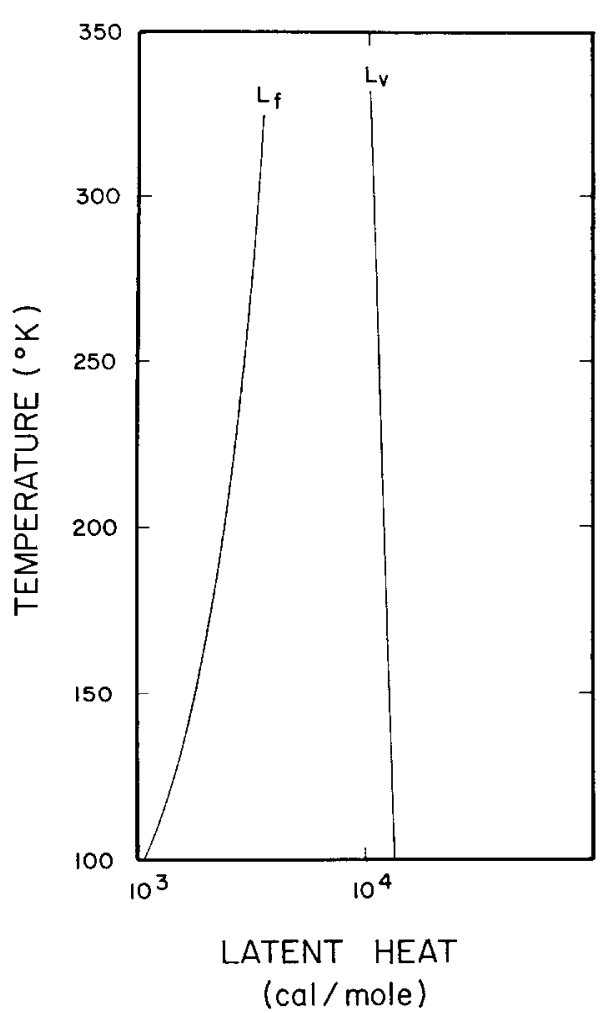

FIG. 3. Saturation vapor density (particles $\mathrm{cm}^{-3}$ ) of $\mathrm{N}_{2} \mathrm{H}_{4}$ as a function of temperature from considerations of the latent heat of sublimation. The value of saturation vapor density of $\mathrm{N}_{2} \mathrm{H}_{4}$ at $100^{\circ} \mathrm{K}$ is 5.6 particles $\mathrm{cm}^{-3}$.

and Ogg (1951) who give empirical expressions for the latent heats of vaporiza- tion $l_{v}$ and fusion $l_{f}$. It was necessary to extrapolate from these expressions to low temperatures since the relation for $l_{v}$ is given for the range from 275 to $1000^{\circ} \mathrm{K}$, while for $l_{f}$ the range is 170 to $340^{\circ} \mathrm{K}$. The temperature variation of the latent heats is not large (see Fig. 3) and we have estimated the latent heat of sublimation $l_{s} \sim l_{v}+l_{f}$ to be $1.4 \times 10^{4} \mathrm{cal} / \mathrm{mole}$. The only measurement of which we are aware of the $\mathrm{N}_{2} \mathrm{H}_{4}$ vapor pressure over $\mathrm{N}_{2} \mathrm{H}_{4}$ ice is that of Scott et al. (1949), who find a pressure of $2.6 \mathrm{~mm} \mathrm{Hg}$ at $273^{\circ} \mathrm{K}$. From these data and the Clausius-Clapeyron equation, we find for the hydrazine saturation number density,

$$
\begin{aligned}
{\left[\mathrm{N}_{2} \mathrm{H}_{4}\right]_{s}=} & \left(2.48 \times 10^{19} / T\right) \\
& \times \exp [25.8(1-273 / T)] .
\end{aligned}
$$

Note that over the temperature range of interest $\left(\sim 110\right.$ to $\left.165^{\circ} \mathrm{K}\right)$ the saturation vapor density varies by about nine orders of magnitude (see Fig. 4). We have not used the Antoine equation (Scott et al., 1949) to estimate the saturation vapor pressure of $\mathrm{N}_{2} \mathrm{H}_{4}$ since the expression was developed for the liquid-vapor phases. If this equation is extrapolated to the lower temperatures applicable to Jupiter, the difference between (1) and Antoine's equation varies up to a factor of 100 .

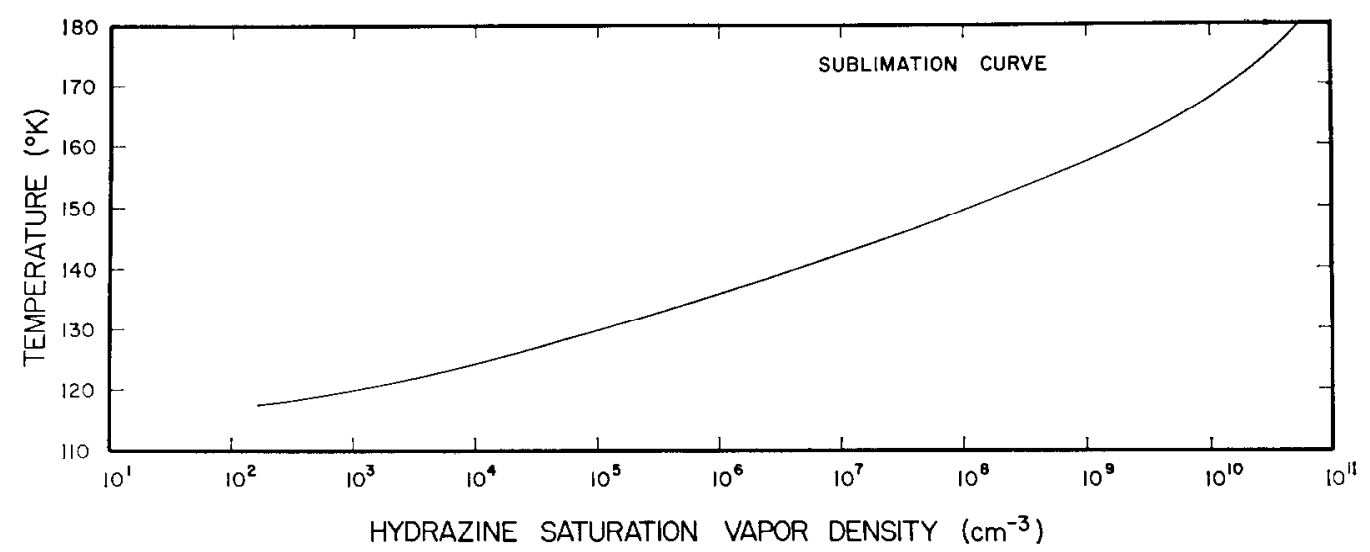

FIG. 4. Variation of the hydrazine latent heat of fusion $l_{f}$ and latent heat of vaporization $l_{v}$ with temperature. 
The $\mathrm{N}_{2} \mathrm{H}_{4}$ concentrations which allow no supersaturation in Fig. 2 correspond to the saturation mixing ratio at the local temperature; i.e., the saturation value was less than the $\mathrm{N}_{2} \mathrm{H}_{4}$ calculated in the photochemical scheme which includes no condensation. If the atmosphere can sustain no more $\mathrm{N}_{2} \mathrm{H}_{4}$ in the gaseous phase than given by the saturation curve, the rest must be available for condensation. These two profiles which differ by many orders of magnitude over the altitude range represent the extremes for gaseous $\mathrm{N}_{2} \mathrm{H}_{4}$. The trend toward a positive gradient around $40 \mathrm{~km}$ is due to the temperature inversion near this altitude.

The nitrogen concentration corresponding to the hydrazine saturation density is about a factor of $3 \times 10^{2}$ smaller near the cloud layer than the nitrogen calculated without any hydrazine condensation; at $40 \mathrm{~km}$, however, the difference is about four orders of magnitude. The resultant $\mathrm{N}_{2} \mathrm{H}_{3}$ is several orders of magnitude less than hydrazine.

Mixing ratio profiles of $\mathrm{NH}_{3}$ are shown for several variations of eddy coefficient in Fig. 5. For comparison we also show, by dotted line, Strobel's (1973) results calculated on the basis of a constant temperature of $120^{\circ} \mathrm{K}$, a constant eddy diffusion coefficient $K=2 \times 10^{4} \mathrm{~cm}^{2} \mathrm{sec}^{-1}$, and a rate constant $k_{4}$ as given by Francis and Jones (1971). Although Strobel's (1973) results appear similar to the model with $K \propto 1 / M^{1 / 2}$ in the present study, this is somewhat fortuitous. For example, using Strobel's reaction scheme and his model atmosphere, but with revised solar flux data and cross sections, we find $\mathrm{NH}_{3}$ concentrations near $40 \mathrm{~km}$ to be some two orders of magnitude smaller than in the previous study. The present calculations apply to a mid-latitude case except for the long dashed curve which is for high latitude. One finds a wide variation in the $\mathrm{NH}_{3}$ mixing ratio near the top with the choice of atmospheric parameters.

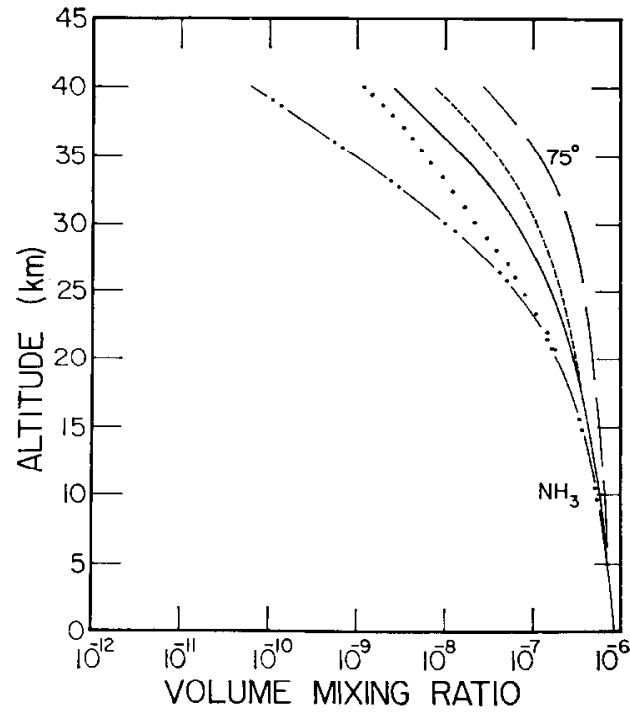

FIG. 5. Variation of ammonia mixing ratio with height for the various atmospheric models. The height scale is the same as in Fig. 1. - .., $T(z)$, $K=2 \times 10^{4} \mathrm{~cm}^{2} \mathrm{sec}^{-1}$ (constant); $\longrightarrow, T(z)$, $K \propto 1 / M^{1 / 2} ;---, T(z), K \propto 1 / M ;--, T(z)$, $K \propto 1 / M^{1 / 2}$, latitude $=75^{\circ} ; \cdots$, Strobel $(1973)$.

As we have discussed earlier, perhaps the representative $\mathrm{NH}_{3}$ distribution in the atmosphere of Jupiter is the one with $K \propto 1 / M^{1 / 2}$, although the variation of $\mathrm{NH}_{3}$ in this model and the one in which $K \propto 1 / M$ is rather small.

There may be an appreciable variation in the ammonia concentration with latitude. At $75^{\circ}$, for example, the column abundance above $20 \mathrm{~km}$ is $5.3 \times 10^{18} \mathrm{~cm}^{-2}$ while the mean global model yields about $2.7 \times 10^{18} \mathrm{~cm}^{-2}$. At the equator the column abundance would be lower; latitudinal variations in $\mathrm{NH}_{3}$ concentration between equator and pole above $30 \mathrm{~km}$ may be larger than two orders of magnitude if meridional transport is negligible. There may be significant variations in $\mathrm{NH}_{3}$ from the mean global model due to the varying solar zenith angle as well as diurnal variations in the photolysis products. At nighttime, there is little variation in $\mathrm{NH}_{3}$, but $\mathrm{NH}_{2}$ (see Fig. 6) decays rapidly to $\mathrm{N}_{2} \mathrm{H}_{4}$ 


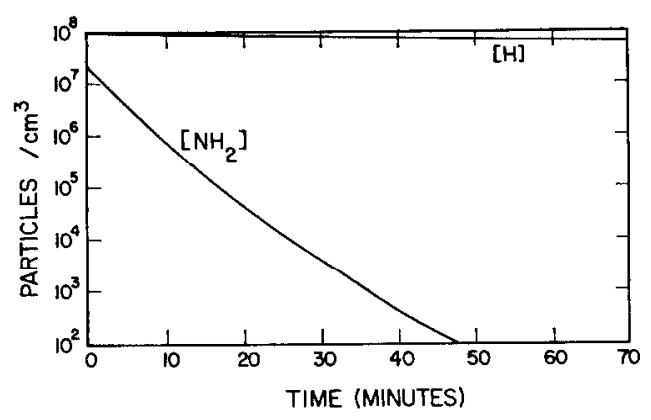

FIG, 6. Variation of $\mathrm{NH}_{2}$ and $\mathrm{H}$ at night in the Jovian atmosphere. The height is approximately $20 \mathrm{~km}$.

with a relaxation time of about $5 \mathrm{~min}$. These calculations assumed the steadystate model as the initial condition and the photochemical equations were solved by the Runge-Kutta method. A study of the full time-dependent problem is in progress and will be reported subsequently.

\section{CONCLUDING REMARKS}

Jovian ammonia chemistry has been reevaluated in the light of improved solar flux data, chemical reactions, reaction rates, eddy diffusion coefficients, and temperature structure. The hydrazine column density above the ammonia cloud top can vary from $1 \times 10^{15}$ to $6 \times 10^{17} \mathrm{~cm}^{-2}$ depending upon the degree of supersaturation. If saturation does not occur then virtually all the hydrazine produced would condense with the total $\mathrm{N}_{2} \mathrm{H}_{4}$ ice production rate of $6.9 \times 10^{10}$ molecules $\mathrm{cm}^{-2} \mathrm{sec}^{-1}$ which corresponds to an amount of about $1.3 \mathrm{mg} \mathrm{m}^{-2}$ per Jovian day.

Nitrogen is the principal gaseous component of ammonia photochemistry. Its column abundance would vary with the degree of hydrazine saturation. Typical $\mathrm{N}_{2}$ column densities should be about $3 \times 10^{-5}$ $\mathrm{cm}$ amagat if there is no supersaturation of hydrazine, while if all the hydrazine remains in the gaseous state the column abundance would be about $3.4 \times 10^{-2} \mathrm{~cm}$ amagat. These calculations assumed an eddy diffusion coefficient at the ammonia cloud top of $2 \times 10^{4} \mathrm{~cm}^{2} \mathrm{sec}^{-1}$; however, an eddy diffusion coefficient of $2 \times 10^{3} \mathrm{~cm}^{2}$ $\sec ^{-1}$ produces an $\mathrm{N}_{2}$ concentration two orders of magnitude larger. If the value of $K_{0}$ were as small as $2 \times 10^{2} \mathrm{~cm}^{2} \mathrm{sec}^{-1}$ as suggested by Sagan and Salpeter (1976), the $\mathrm{N}_{2}$ Inixing ratio would be on the order of $10^{-7}$. The $\mathrm{N}_{2}$ concentration we estimate near the ammonia cloud top may be within the realm of in situ detection with the present mass spectrometers, particularly those utilizing enrichment techniques.

The mean global ammonia profiles which we calculate are similar to the earlier study by Strobel (1973), i.e., the ammonia destruction rates are within a factor of 2 . However, there may be significant latitudinal variations. In high latitudes, the column abundance because of a larger effective zenith angle is most likely several times that at the equator. The results presented here are strongly dependent on the eddy diffusion coefficient. For example, a decrease in the value of the eddy diffusion coefficient from $2 \times 10^{4}$ to $2 \times 10^{3} \mathrm{~cm}^{2} \mathrm{sec}^{-1}$ at the ammonia cloud top results in about a sevenfold decrease in the column abundance of ammonia.

The range of distributions of $\mathrm{N}_{2} \mathrm{H}_{4}$, $\mathrm{N}_{2} \mathrm{H}_{3}$, and $\mathrm{N}_{2}$ gases presented in this paper relies on the vapor pressure of $\mathrm{N}_{2} \mathrm{H}_{4}$ which we approximated from the Clausius-Clapeyron equation. A precise measurement of the hydrazine vapor pressure at the low temperatures $\left(110-165^{\circ} \mathrm{K}\right)$ prevalent in the lower atmosphere of Jupiter is highly desirable.

\section{ACKNOWLEDGMENTS}

We have benefited from discussion with $G$. $R$. Carignan, S. Chang, B. C. Kennedy, L. J. Stief, D. F. Strobel, and S. Walters. This research was supported in part by NASA under Grants AURA86303 (NASA/JPL Contract 7-100), NAS2-8992, and $\mathrm{A} 17362 \mathrm{~B}$.

\section{REFERENCES}

ACkerman, M. (1971). Ultraviolet solar radiation related to mesospheric processes. In Mesospheric 
Models and Related Experiments (G. Fioceo, Ed.), p. 149. Reidel, Dordrecht.

Ames, W. F. (1969). Numerical Methods for Partial Differential Equations. Barnes and Noble, New York.

Audreith, L. F., ANd OGG, R. A. (1951). The Chemistry of Hydrazine. Wiley, New York.

Barker, E. S. (1976). Personal communication and paper presented at the Division of Planetary Science, 7th Annual Meeting, Austin, Texas, 31 March, 1976.

Carlson, R. W., and Judge, D. L. (1974). Pioneer 10 ultraviolet photometer observations at Jupiter encounter. I. Geophys. Res. 79, 3623.

Ebrrstein, I. J., and Glassman I. (1965). The gas phase decomposition of hydrazine and its methyl derivative. In Pros. Xth Symposium (International) on Combustion, p. 365 . The Combustion Institute, Princeton, N. J.

Francis, P. D., and Jones A. R. (1971). ESR measurement reaction between $\mathrm{H}$ atoms and $\mathrm{N}_{2} \mathrm{H}_{4}$. J. Chem. Phys. 54, 5085.

Gehring, M., Hoyermann, G., Wagner, H. G., AND Wolfrum, J. (1969). Reaction of atomic hydrogen with hydrazine. Ber. Bunsenges. Phys. Chem. 73, 956.

Gorden, S., Mulac, W., and Nangia, P. (1971). Pulse radiolysis of ammonia gas. II. Rate of disappearance of the $\mathrm{NH}_{2}\left(X^{2} B_{1}\right)$ radicul. J. Phys. Chem. 75, 2087.

Ham, D. O., Trainor, D. W., and Kaufman, F. (1970). Gas phase kinetics of $\mathrm{H}+\mathrm{H}+\mathrm{H}_{2} \rightarrow 2 \mathrm{H}_{2}$. J. Chem. Phys. 53, 4395.

Hunten, D. M. (1976). Atmospheres and iono- spheres. In Jupiter (T. Gehrels, Ed.), p. 21. University of Arizona, Tueson.

Lindzen, R. S. (1971). In Mesospheric Models and Related Experiments (G. Fiocco, Ed.), p. 122. Reidel, Dordrecht.

Sagan, C., and Salpeter, E. E. (1976). Particles, environments, and possible ecologies in the Jovian atmosphere. Astrophys. $J .32,737$.

Schürgers, M., ANd Welge, K. H. (1968). Absorptionkoeffizient von $\mathrm{H}_{2} \mathrm{O}_{2}$ and $\mathrm{N}_{2} \mathrm{H}_{4}$ zwischen 1200 und $2000 \AA$ A. Z. Naturforsch. A 23, 1508.

Schurath, U., und Schindler, R. N. (1970). The photolysis of hydrazine at $2060 \AA$ in the presence of ethylene. J. Phys. Chem. 74, 3188.

Scott, D. W., Oliver, G. D., Gross, M. E., Hubbard, W. N., and Huffman, H. M. (1949). Hydrazine: Heat capacity, heats of fusion and vaporization, vapor pressure, entropy and thermodynamic functions. J. Amer. Chem. Soc. 71, 2293.

Stiff, L. J., and Payne, W. A. (1976). Absolute rate parameter for the reaction of atomic hydrogen with hydrazine. J. Chem. Phys. 64, 4892.

Strobel, D. F. (1973). The photochemistry of $\mathrm{NH}_{3}$ in the Jovian atmosphere. J. Atmos. Sci. 30, 1205.

Thompson, B. A., Harteck, P., and Reeves, R. R., JR. (1963). Ultraviolet absorption coefficients of $\mathrm{CO}_{2}, \mathrm{CO}, \mathrm{O}_{2}, \mathrm{H}_{2} \mathrm{O}, \mathrm{N}_{2} \mathrm{O}, \mathrm{NII}_{3}, \mathrm{NO}, \mathrm{SO}_{2}$, and $\mathrm{CII}_{4}$ between 1850 and $4000 \AA$. J. Geophys. Res. 68, 6431.

Tomasko, M. G. (1974). Ammonia absorption relevant to the albedo of Jupiter. II. Interpretation. Astrophys. J. 187, 641.

Watanabe, K. (1954). Photoionization and total absorption cross section of gases. I. Ionization potential of several molecules. Cross sections of $\mathrm{NH}_{3}$ and NO. J. Chem. Phys. 22, 1564. 